\title{
Breathing adapted radiotherapy: a 4D gating software for lung cancer
}

\author{
Nicolas Peguret ${ }^{1 *}$, Jacqueline Vock ${ }^{1}$, Vincent Vinh-Hung ${ }^{1}$, Pascal Fenoglietto ${ }^{3}$, David Azria ${ }^{3}$, Habib Zaidi $^{2}$, \\ Michael Wissmeyer ${ }^{2}$, Osman Ratib² and Raymond Miralbell ${ }^{1}$
}

\begin{abstract}
Purpose: Physiological respiratory motion of tumors growing in the lung can be corrected with respiratory gating when treated with radiotherapy (RT). The optimal respiratory phase for beam-on may be assessed with a respiratory phase optimizer (RPO), a 4D image processing software developed with this purpose.
\end{abstract}

Methods and Materials: Fourteen patients with lung cancer were included in the study. Every patient underwent a 4D-CT providing ten datasets of ten phases of the respiratory cycle (0-100\% of the cycle). We defined two morphological parameters for comparison of 4D-CT images in different respiratory phases: tumor-volume to lungvolume ratio and tumor-to-spinal cord distance. The RPO automatized the calculations (200 per patient) of these parameters for each phase of the respiratory cycle allowing to determine the optimal interval for RT.

Results: Lower lobe lung tumors not attached to the diaphragm presented with the largest motion with breathing. Maximum inspiration was considered the optimal phase for treatment in 4 patients (28.6\%). In 7 patients (50\%), however, the RPO showed a most favorable volumetric and spatial configuration in phases other than maximum inspiration. In 2 cases (14.4\%) the RPO showed no benefit from gating. This tool was not conclusive in only one case.

Conclusions: The RPO software presented in this study can help to determine the optimal respiratory phase for gated RT based on a few simple morphological parameters. Easy to apply in daily routine, it may be a useful tool for selecting patients who might benefit from breathing adapted RT.

Keywords: Lung cancer, radiotherapy, 4D-CT, gating

\section{Introduction}

Lung cancer is the first cause of cancer death in the world with an overall 5 year survival rate inferior to $15 \%$. It has been shown that local control after radiotherapy (RT) is dose-dependent with a better overallsurvival for patients with the disease locally controlled [1-3]. Nevertheless, physiological respiratory motion of primary lung tumors may challenge the chances of obtaining an optimal local control rate after RT.

There are presently several approaches under investigation aiming to correct for tumor motion potentially leading to a better conformality of RT: tumor tracking, synchronizing the beam-on/beam-off time with respiratory motion (gating), or using $4 \mathrm{D}-\mathrm{CT}$ to determine the

\footnotetext{
* Correspondence: Nicolas.Peguret@hcuge.ch

'Department of Radiation Oncology, University Hospital, Geneva, Switzerland Full list of author information is available at the end of the article
}

average tumor motion during a respiratory cycle in order to define an internal target volume [4-7]. A 4D$\mathrm{CT}$ acquires sets of images in different respiratory phases and can be employed for respiratory gated radiotherapy [8]. Systematic errors can thus be reduced and reliable target margins can be defined, in order to avoid the risk of underdosing due to tumor motion [9]. Respiratory gating has been shown to reduce the size of the planning treatment volume (PTV) defined by $4 \mathrm{D}-\mathrm{CT}$ and is expected to improve the therapeutic ratio by raising the dose to the tumor and decreasing the dose to the surrounding normal tissues $[10,11]$.

Although there are techniques compensating for respiratory motion during $\mathrm{RT}$ and delivering $\mathrm{RT}$ during one specific moment of the respiratory cycle, the optimal moment for delivering RT remains unknown and controversial. Irradiation during deep inspiratory breath

C Biomed Central

(c) 2011 Peguret et al; licensee BioMed Central Ltd. This is an Open Access article distributed under the terms of the Creative Commons Attribution License (http://creativecommons.org/licenses/by/2.0), which permits unrestricted use, distribution, and reproduction in any medium, provided the original work is properly cited. 
hold (DIBH) is considered by some to have dosimetric advantages in terms of lung sparing through the inspiratory expansion of the healthy lung tissue $[12,13]$. However, DIBH may not be feasible in patients with compromised pulmonary function. On the other hand, end-expiration is considered to be more reliable by others because it is longer and more reproducible than end-inspiration [14].

In this report we present a respiratory phase optimizer (RPO) for breathing adapted RT (BART) in order to determine the optimal irradiation phase based on a few simple morphological parameters.

\section{Methods and Materials}

Fourteen patients with a primary or recurrent lung cancer were retrospectively studied. 4D-CTs were acquired during 4 to 6 respiratory cycles for every patient in the study. Patient data sets were provided by the Geneva University Hospital (6 cases), the CRLC Val d'Aurelle (6 cases), and by the General Electric Corporation (2 cases).

Ten 4D-CT axial images corresponding to ten time bins (phases) of the respiratory cycle (i.e., in 10\% increments) were reconstructed, using a maximum intensity projection (MIP) system (Figure 1). The MIP (maximum intensity projection) is a visualization method for $3 \mathrm{D}$ imaging data. It was first described by Wallis et al. originally called "maximum activity projection", for nuclear medicine use [15]. It is now widely employed in radiology and in particular for 4D-CT [16]. During the 4D image acquisition, the scan extracts information continuously during a time interval equivalent to a breathing cycle. After that, and using an external physiological signal, the ADW (advantage workstation) system can reconstruct retrospectively $10 \mathrm{CT}$ sets, each of them representing an acquisition on the same breathing phase. Therefore, our cam gets $10 \mathrm{CT}$-scans equivalent to 10 breathhold positions. For the same slice coordinates, 10 different values for the same voxel in the DICOM reference are obtained. A MIP can be created by building a new image, looking for the maximum value of the 10 different scans in the corresponding voxel. In Geneva, the MIP system was implemented by a commercial software provided on the Biograph TP 64 scanner (Syngo software, Siemens Medical Solutions, Erlangen, Germany). A time reference for the 4D image datasets was obtained with the Real-Time Position Management system (RPM, Varian Medical Systems Inc., Palo Alto, CA) for 8 patients and the Anzai system (Anzai AZ-733V system, Anzai Medical Co, Ltd., Tokyo, Japan) for 6 patients.

As shown in Figure 1, two parameters were defined to compare the images of each phase: a) the target to lung volume ratio $\left(\mathrm{T} / \mathrm{L}\right.$ ratio $\left._{\mathrm{vol}}\right)$, ideally as small as possible and $b)$ the tumor to spinal cord distance $\left(T-C_{\text {dist }}\right)$, sought to be as large as possible. A low $\mathrm{T} / \mathrm{L}$ ratio $_{\text {vol }}$ may obviously result in optimal target coverage with a simultaneous reduced lung irradiation. DIBH has shown the potential for a reduced lung V20 (i.e., percent of lung volume receiving 20 Gy) [12]. Choosing the phase where $\mathrm{T}-\mathrm{C}_{\text {dist }}$ is the largest is based on the fact that dose constraints to the spinal cord have the highest priority in ongoing trials [17]. An image processing software ("Myr$\operatorname{ian}^{\mathbb{B}}$, developed by the Intrasense Company, Montpellier, France) was used for delineation and volume determination of the tumor and OARs (Figure 2). The external limits of the target and of the OARs were defined on images derived directly from a DICOM CD to work with usable cross sections. All the contouring was done by the same author (NP). The segmentation of the gross tumor volume (GTV) and of the OARs (lungs and spinal cord) is done by "Myrian ${ }^{\circledR}$ " semi-automatically and automatically, respectively. This process results in the definition of four regions of interest (ROI): the GTV, the right lung, the left lung and, the spinal cord.

Because "Myrian ${ }^{\circledR}$ " is not able in the current version to calculate $\mathrm{T} / \mathrm{L}$ ratio $_{\mathrm{vol}}$ and $\mathrm{T}-\mathrm{C}_{\mathrm{dist}}$, all these data are then transferred to the RPO, where their calculations and graphical presentation are automatized for each respiratory phase. In this process, "Myrian ${ }^{\circledR}$ " is unable to perform an automatic propagation of TV and OAR delineated from one phase to the other nine. So, this sequence is repeated for each of the ten phases of the respiratory cycle and with the CT data acquired in maximal inspiration (the reference). Once the data are collected, the RPO is able to display a bar graph for both comparison parameters: the T/L ratio ${ }_{\mathrm{vol}}$ and the $\mathrm{T}-\mathrm{C}_{\text {dist }}$. A graph displays, in addition, the absolute ipsilateral lung volume measured at each respiratory phase. A synoptic summary of the two graphs is presented to the user who may then proceed to the assessment of the optimal respiratory phase.

For the present study the percentual difference between the optimal respiratory phase and maximal inspiration (the reference) was assessed. If both were coincident, we computed, in addition, the percentual difference between the optimal respiratory phase and the least optimal one. We considered that there was no gain if the difference was $\leq 20 \%$.

\section{Results}

Patients and tumor characteristics are presented in Table 1. The output of the RPO for each individual case is presented in additional file 1: RPO_appendice.doc. Table 2 and Table 3 present, respectively, (T/L ratio ${ }_{\text {vol }}$ ) and $\left(\mathrm{T}-\mathrm{C}_{\text {dist }}\right)$ for the 14 patients according to the ten sequential respiratory phases chosen in our study. 


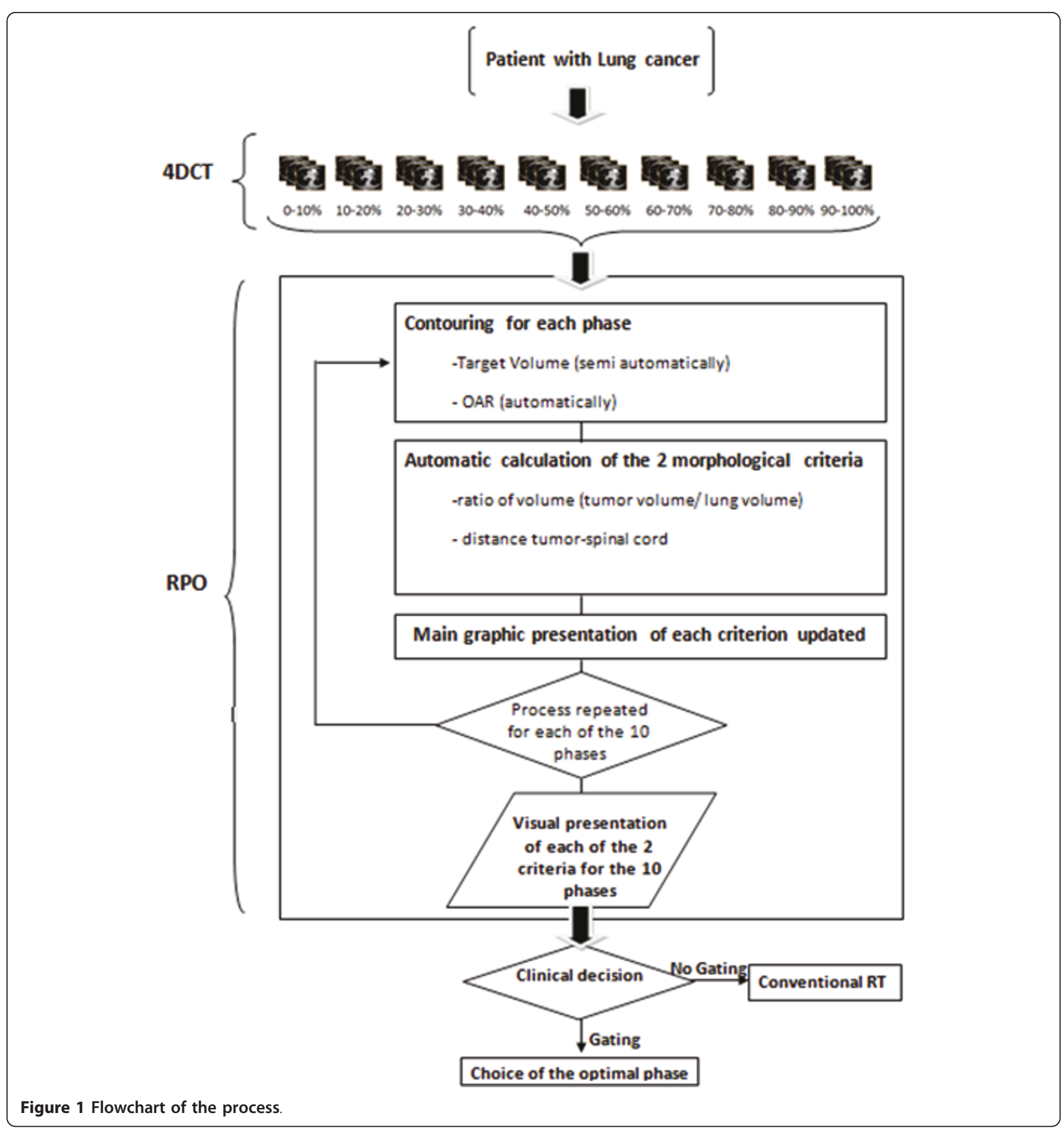

As also shown in Table 2, maximal inspiration occurred mostly at the beginning of the 4D-CT recording: phase $0-9 \%$ in 9 patients and $10-19 \%$ in 4 patients. Only in patient \#9 maximal inspiration occurred during the phase $60-69 \%$ of the respiratory cycle. Concerning the optimal $\mathrm{T} / \mathrm{L}$ ratio $_{\mathrm{vol}}$, the optimal respiratory phase coincided with maximal inspiration in only 6 cases. The mean difference between the optimal respiratory phase and maximal inspiration (the reference) was 15\% (SD \pm
19) ranging from 0 (optimal phase coinciding with maximal inspiration) to $67 \%$. Compared to the worst phase of the respiratory cycle, the mean difference between the optimal phase and the less optimal one was $34 \%$ $(\mathrm{SD} \pm 18)$ ranging from 12 to $79 \%$.

Regarding the second parameter, the $\mathrm{T}-\mathrm{C}_{\text {dist }}$, the optimal phase coincided with maximal inspiration in only 3 cases (Table 3). The mean difference between the optimal respiratory phase and maximal inspiration was $5.5 \%$ 


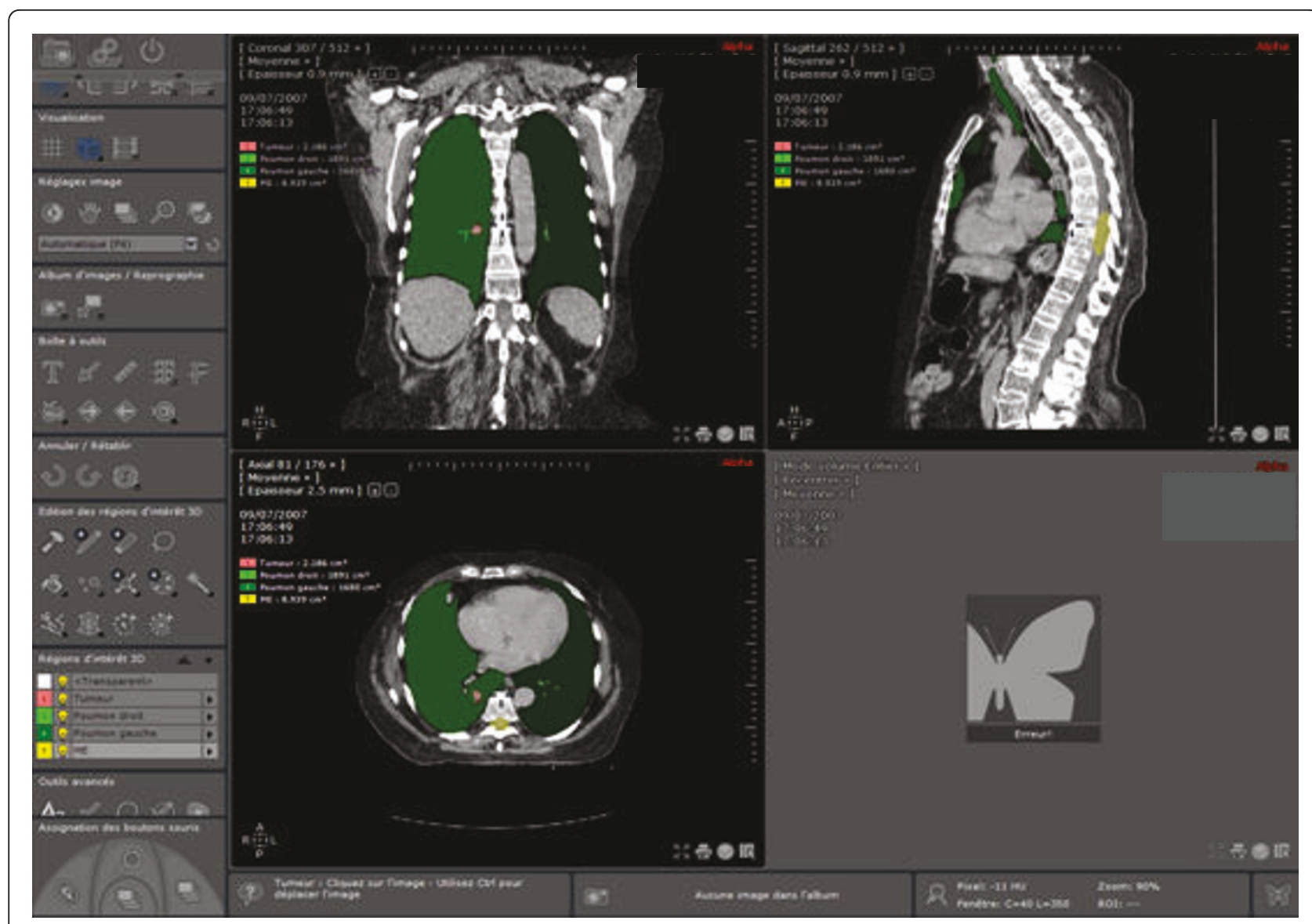

Figure $\mathbf{2}$ Visualization of all the "ROI" necessary to calculate the criteria of comparison.

Table 1 Patients and tumor characteristics

\begin{tabular}{|c|c|c|c|c|c|c|}
\hline Patient & Age & Sex & Site & Stage & Histology & Mean GTV volume $\left(\mathrm{cm}^{3}\right)$ \\
\hline 1 & unknown & M & Right middle lobe & T2NOMO & unknown & 90 \\
\hline 2 & unknown & $F$ & Left lower lobe & TXN2M0 & unknown & 403 \\
\hline 3 & 46 & M & Right paratracheal & TXN3M0 & SCC & 27 \\
\hline 4 & 51 & M & Right upper lobe & T2N2M0 & $\mathrm{NSCLC}$ & 86 \\
\hline 5 & 75 & $\mathrm{~F}$ & Right lower lobe & T1NOMO & $A C$ & 2 \\
\hline 6 & 75 & $F$ & Right lower lobe & T1NOMO & $A C$ & 2 \\
\hline 7 & 71 & M & Right upper lobe & T1NOMO & unknown & 7 \\
\hline 8 & 64 & $F$ & Right upper lobe & T1NOMO & $A C$ & 10 \\
\hline 9 & 62 & M & Left lower lobe & T3NOMO & unknown & 2 \\
\hline 10 & 81 & $F$ & Left lower lobe & T2N1M0 & SCC & 68 \\
\hline 11 & 65 & M & Left upper lobe & Stage IV (M1) & SCC & 37 \\
\hline 12 & 81 & M & Right middle lobe & T2N1M0 & SCC & 66 \\
\hline 13 & 70 & M & Right upper lobe & T1NOMO & $A C$ & 6 \\
\hline 14 & 63 & $\mathrm{~F}$ & Right lower lobe & Extensive. disease & $\mathrm{SCLC}$ & 10 \\
\hline
\end{tabular}


Table 2 Tumor to lung volume parameter ( $\mathrm{T} / \mathrm{L}$ ratio $_{\mathrm{vol}}=100 *$ Tumor volume/lpsilateral lung volume)

\begin{tabular}{|c|c|c|c|c|c|c|c|c|c|c|c|c|c|}
\hline \multirow[t]{2}{*}{ Patient } & \multicolumn{10}{|c|}{ Respiratory phase } & \multirow{2}{*}{$\begin{array}{c}\text { Phase opt }= \\
\text { ref }\end{array}$} & \multirow{2}{*}{$\begin{array}{c}\text { ref } \\
\text { gain opt/ }\end{array}$} & \multirow{2}{*}{$\begin{array}{c}\% \text { gain opt } \\
\text { worst }\end{array}$} \\
\hline & $\begin{array}{c}0- \\
9 \%\end{array}$ & $\begin{array}{c}10- \\
19 \%\end{array}$ & $\begin{array}{c}20- \\
29 \%\end{array}$ & $\begin{array}{c}30- \\
39 \%\end{array}$ & $\begin{array}{c}40- \\
49 \%\end{array}$ & $\begin{array}{c}50- \\
59 \%\end{array}$ & $\begin{array}{l}60- \\
69 \%\end{array}$ & $\begin{array}{c}70- \\
79 \%\end{array}$ & $\begin{array}{l}80- \\
89 \%\end{array}$ & $\begin{array}{c}90- \\
99 \%\end{array}$ & & & \\
\hline 1 & 1.90 & 2.00 & 1.60 & 2.00 & 1.90 & 1.90 & 2.20 & 2.00 & 1.90 & 1.90 & no & 20 & 27 \\
\hline 2 & $\underline{33.5}$ & 35.8 & 44.7 & 56.6 & 65.5 & 71.7 & 71.1 & 59.0 & 45.8 & 37.6 & yes & 0 & 53 \\
\hline 3 & 1.20 & 1.10 & 1.20 & 1.00 & 1.20 & 1.30 & 1.20 & 1.30 & 1.20 & 1.20 & no & 17 & 23 \\
\hline 4 & 5.10 & 6.00 & 5.90 & 6.00 & 6.70 & 6.40 & 6.40 & 6.6 & 6.00 & 5.50 & yes & 0 & 24 \\
\hline 5 & $\underline{0.09}$ & 0.06 & 0.08 & 0.13 & 0.14 & 0.15 & 0.12 & 0.08 & 0.07 & 0.13 & no & 33 & 60 \\
\hline 6 & 0.12 & $\underline{0.04}$ & 0.11 & 0.16 & 0.14 & 0.19 & 0.12 & 0.10 & 0.09 & 0.17 & yes & 67 & 79 \\
\hline 7 & $\underline{0.25}$ & 0.23 & 0.22 & 0.22 & 0.22 & 0.23 & 0.24 & 0.24 & 0.24 & 0.24 & no & 12 & 12 \\
\hline 8 & 0.30 & 0.30 & 0.36 & 0.41 & 0.44 & 0.43 & 0.42 & 0.44 & 0.42 & 0.31 & yes & 0 & 32 \\
\hline 9 & 0.11 & 0.11 & 0.09 & 0.09 & 0.09 & 0.11 & $\underline{0.12}$ & 0.12 & 0.12 & 0.12 & no & 0 & 25 \\
\hline 10 & 5.50 & 5.60 & 5.80 & 5.90 & 5.90 & 6.70 & 6.30 & 5.90 & 5.70 & 6.10 & yes & 0 & 18 \\
\hline 11 & 2.75 & $\underline{2.15}$ & 1.76 & 1.86 & 1.53 & 1.90 & 2.15 & 1.95 & 2.18 & 2.64 & no & 29 & 44 \\
\hline 12 & 5.50 & 5.70 & 5.20 & 5.60 & 4.70 & 3.80 & 4.50 & 4.70 & 4.80 & 5.30 & no & 31 & 33 \\
\hline 13 & 0.26 & $\underline{0.26}$ & 0.26 & 0.27 & 0.25 & 0.32 & 0.32 & 0.32 & 0.31 & 0.26 & no & 4 & 22 \\
\hline 14 & 0.40 & 0.42 & 0.47 & 0.48 & 0.40 & 0.44 & 0.52 & 0.44 & 0.40 & 0.40 & yes & 0 & 23 \\
\hline
\end{tabular}

Phase where maximal inspiration was observed is indicated by underlining

Ref $=$ maximal inspiration, opt $=$ optimal phase found by RPO, worst $=$ worst phase found by RPO

$(\mathrm{SD} \pm 7.0)$ ranging from 0 to $27 \%$. Compared to the worst phase of the respiratory cycle, the mean difference between the optimal phase and the less optimal one was $10 \%$ (SD \pm 11 ) ranging from 2 to $46 \%$.

With a cut-off of $20 \%$ only 2 cases showed no benefit in either of both parameters (patients \#7 and \#10). In 11 patients, however, a substantial gain was observed for the $\mathrm{T} / \mathrm{L}$ ratio $_{\mathrm{vol}}$, the optimal phase coinciding with maximal inspiration in $4(28.6 \%)$ and differing from maximal inspiration in 7 (50\%). In only one patient (7\%) (Patient
\#4) maximal inspiration was optimal for the $\mathrm{T} / \mathrm{L}$ ratio ${ }_{\mathrm{vol}}$, but was suboptimal for the $\mathrm{T}-\mathrm{C}_{\text {dist }}$ Figure 3 displays the corresponding overall summary.

\section{Discussion}

Physiological respiratory motion is a major challenge for lung cancer RT. The range of motion can reach an average up to $12 \pm 6 \mathrm{~mm}$ for tumors in the lower lung lobes [18]. Giraud et al., observed large diaphragm displacements in the cranio-caudal direction during free

Table 3 Tumor to spinal cord distance parameter $\left(T-C_{\text {dist }}\right)$ in $\mathbf{m m}$.

\begin{tabular}{|c|c|c|c|c|c|c|c|c|c|c|c|c|c|}
\hline \multirow[t]{2}{*}{ Patient } & \multicolumn{10}{|c|}{ Respiratory phase } & \multirow{2}{*}{$\begin{array}{c}\text { Phase opt }= \\
\text { ref }\end{array}$} & \multirow{2}{*}{$\begin{array}{l}\% \text { gain opt } / \\
\text { ref }\end{array}$} & \multirow{2}{*}{$\begin{array}{c}\% \text { gain opt } \\
\text { worst }\end{array}$} \\
\hline & $\begin{array}{c}0- \\
9 \%\end{array}$ & $\begin{array}{l}10- \\
19 \%\end{array}$ & $\begin{array}{l}20- \\
29 \%\end{array}$ & $\begin{array}{c}30- \\
39 \%\end{array}$ & $\begin{array}{c}40- \\
49 \%\end{array}$ & $\begin{array}{l}50- \\
59 \%\end{array}$ & $\begin{array}{l}60- \\
69 \%\end{array}$ & $\begin{array}{l}70- \\
79 \%\end{array}$ & $\begin{array}{l}80- \\
89 \%\end{array}$ & $\begin{array}{l}90- \\
99 \%\end{array}$ & & & \\
\hline 1 & 165 & 164 & 163 & 167 & 170 & 167 & 168 & 166 & 165 & 164 & no & 4 & 4 \\
\hline 2 & 66 & 67 & 66 & 68 & 69 & 68 & 67 & 69 & 66 & 67 & no & 5 & 5 \\
\hline 3 & $\underline{63}$ & 61 & 57 & 60 & 60 & 58 & 61 & 60 & 58 & 58 & yes & 0 & 11 \\
\hline 4 & $\underline{75}$ & 91 & 95 & 91 & 65 & 70 & 70 & 72 & 79 & 74 & no & 27 & 46 \\
\hline 5 & $\underline{43}$ & 41 & 42 & 41 & 41 & 40 & 40 & 38 & 37 & 40 & yes & 0 & 16 \\
\hline 6 & 40 & $\underline{43}$ & 41 & 41 & 44 & 43 & 39 & 41 & 40 & 42 & no & 10 & 13 \\
\hline 7 & $\underline{115}$ & 115 & 114 & 115 & 115 & 114 & 116 & 113 & 115 & 115 & no & 1 & 3 \\
\hline 8 & 126 & 129 & 129 & 128 & 127 & 128 & 128 & 126 & 126 & 127 & no & 2 & 2 \\
\hline 9 & 72 & 72 & 72 & 71 & 72 & 70 & $\underline{71}$ & 72 & 71 & 71 & no & 0 & 3 \\
\hline 10 & $\underline{47}$ & 50 & 50 & 48 & 47 & 47 & 51 & 51 & 49 & 49 & no & 9 & 9 \\
\hline 11 & 74 & $\underline{70}$ & 72 & 70 & 70 & 71 & 73 & 72 & 70 & 71 & no & 6 & 6 \\
\hline 12 & 61 & 60 & 58 & 61 & 63 & 61 & 64 & 63 & 64 & 68 & no & 11 & 17 \\
\hline 13 & 83 & $\underline{84}$ & 84 & 84 & 84 & 84 & 84 & 84 & 85 & 84 & no & 2 & 2 \\
\hline 14 & 92 & 90 & 89 & 88 & 89 & 90 & 90 & 90 & 88 & 88 & yes & 0 & 5 \\
\hline
\end{tabular}

Phase where maximal inspiration was observed is indicated by underlining

Ref $=$ maximal inspiration, opt $=$ optimal phase found by RPO, worst $=$ worst phase found by RPO 


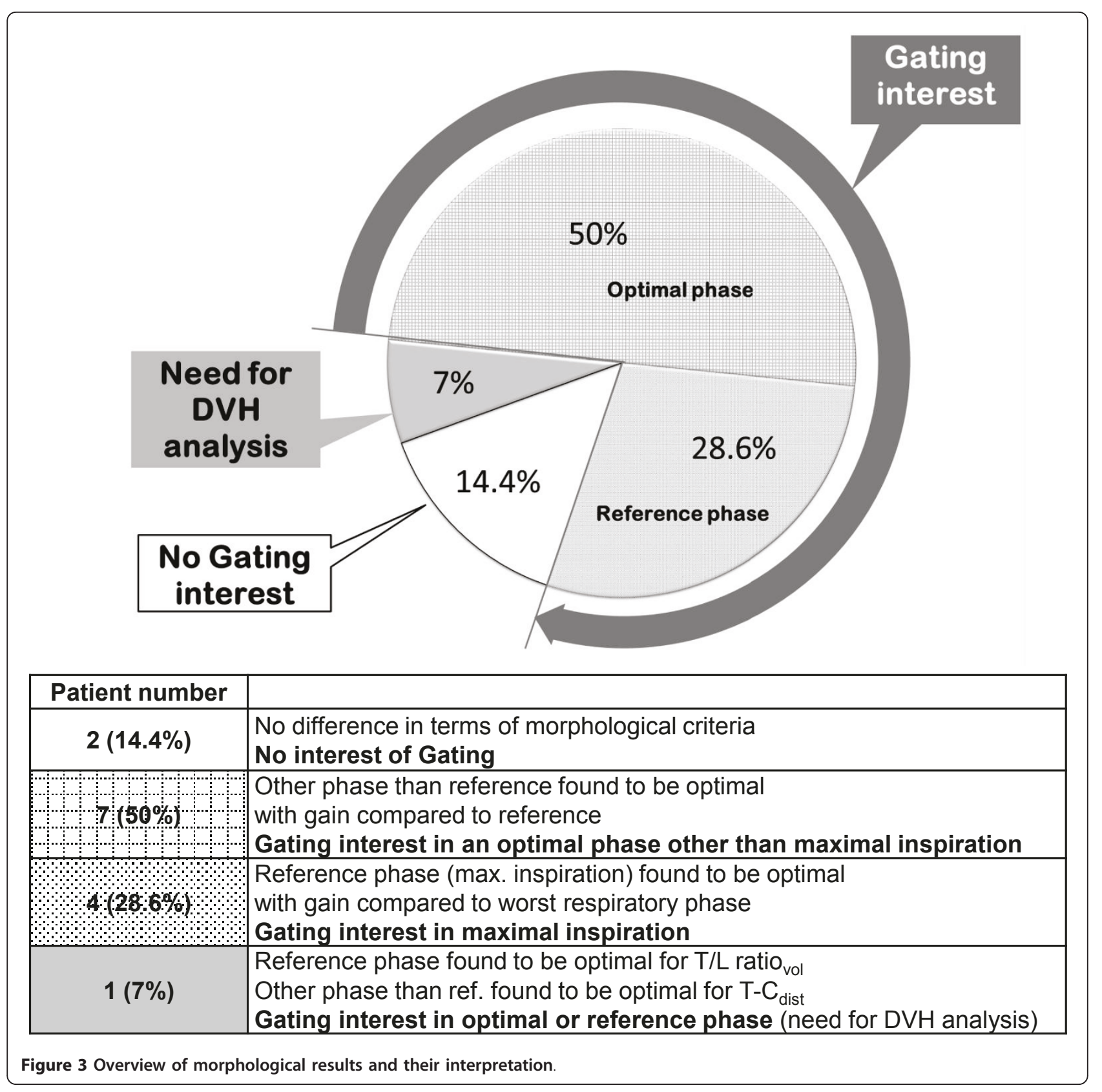

breathing with an average range of $34 \mathrm{~mm}$ and a maximum of $67 \mathrm{~mm}$ between inspiration and expiration. Reduced motion, however, has been reported for tumors in the lung apices with an average of $8 \mathrm{~mm}$ displacement in the cranio-caudal direction between inspiration and expiration [19]. A patient's breathing pattern varies from day to day (inter-fraction motion) and can vary during an individual RT fraction (intra-fraction motion) [20]. As a consequence of respiratory motion, planning target volume (PTV) margins in the order of $1.5-2 \mathrm{~cm}$ are commonly used for RT without breathing control. These margins increase, obviously, the irradiated lung volume and consequently the risk of pulmonary radiation toxicity [21]. The most consistent and predictive parameters for radiation induced lung toxicity are the V20 and the mean lung dose (MLD) [22,23]. It is widely accepted that keeping V20 <30-37\% and MLD <20Gy may yield a relatively low risk of pneumonitis $(<20 \%)$.

Our findings are consistent with Giraud et al., in his analysis of intrathoracic organ motion during breathing 
[19]. Indeed, tumors growing in the lower lung lobes and not attached to the diaphragm (i.e., patients \#2, \#5, $\# 6$, \#9, \#10, and \#14) presented with large variation of $\mathrm{T} /$ $\mathrm{L}$ ratio ${ }_{\mathrm{vol}}$ or $\mathrm{T}-\mathrm{C}_{\mathrm{dist}}$, translating in a potential benefit from respiratory gating techniques. Giraud et al., observed also that the smallest displacements were in the apices and near the tracheal carina. This is in agreement with our observation that centrally located tumors may benefit less from gating based on the present algorithm, especially when fibrous attachments to the mediastinum restrict their mobility (e.g., patient \#3). Five tumors growing in the superior lung regions (i.e., patients \#4, \#7, \#8, $\# 11$, and \#13) presented less, though not negligible, changes in the chosen comparative parameters. For patients with tumors growing in the posterior mediastinum, close to the spinal cord, the RPO helped to find the optimal respiratory phase other than maximal inspiration (i.e., patient \#4). Maximum inspiration, the reference, was optimal in only $28.6 \%$ of cases (Figure 3 ). In $50 \%$, however, other phases of the respiratory cycle were found to be optimal as identified by RPO.

Although, gating techniques are reasonably time consuming, and they may not be needed for every patient. A threshold of tumor motion or tumor volume needs to be defined above which gating can be recommended. Starkschall et al., found that patients with small tumors $($ GTV $<100 \mathrm{~cm} 3)$ benefitted the most from gating [24]. Therefore, the RPO software may also help to identify patients with minimal tumor motion influence for whom a gating-free treatment can be recommended.

Easy to apply in daily routine, fast in getting the optimization result, and no special hardware needed are the main practical advantages of the RPO worth to be highlighted. It is important, however, to plan on a $4 \mathrm{D}-\mathrm{CT}$ to be able to acquire synchronized image sets. Data analysis represents about 2000 calculations (volumes, densities, surfaces, inertia axes, density histograms, ratio of volumes, and distances) for every patient.

Variability in target volume delineation is a major source of error in 4D-CT treatment planning. Because all the contours were defined by the same author, interobserver variability was unavailable in our study in response to the need of technique novelties claimed in some recent literature in the $4 \mathrm{D}-\mathrm{CT}$ era [25]. In a new version of the Myrian software, a contour propagation tool has been integrated which is expected to reduce intra-observer variability, but the accuracy of this tool needs to be investigated in a dedicated study before implementation in clinical routine.

An evident limitation of our study is the reduced number of patients studied so far and the restricted morphological parameters of the comparison not including dose-volume parameters in the analysis. Nevertheless, it seems reasonable to assume a dosimetric gain when treating patients in the optimal respiratory phase selected by the RPO.

Further development of the presented software is planned in order to adapt it for tumor locations in the upper abdomen as treatment reproducibility may also be conditioned by respiratory motion. In addition, the density histograms obtained with "Myrian ${ }^{\circledR}$ " may also be used to assess the treatment response after treatment.

\section{Conclusion}

The RPO software presented in this study can help to determine the optimal respiratory phase for gated RT based on a few simple morphological parameters. Easy to apply in daily routine, it may be a useful tool for selecting patients who might benefit from BART.

\section{Additional material}

Additional file 1: Appendices.

\section{Acknowledgements}

We would like to thank Jean B Dubois and Antoine Serre for their initial conceptual and logistic help in this project. We also underline the great cooperation with the team of Intrasense Company, specially Stephane Chemouny and Frederic Banegas for their unfailing help to solve technical issues during this study.

\section{Consent}

Written informed consent was obtained from the Geneva's patient for publication and accompanying images. A copy of the written consent is available for review by the Editor-in-Chief of this journal.

\section{Author details}

${ }^{1}$ Department of Radiation Oncology, University Hospital, Geneva, Switzerland. ${ }^{2}$ Department of Nuclear Medicine, University Hospital, Geneva, Switzerland.

${ }^{3}$ Department of Radiation Oncology, CRLC Val d'Aurelle, Montpellier, France.

\section{Authors' contributions}

NP conceived the RPO software, provided and cared for study patients, performed all target volume and OAR delineation, contributed to data acquisition and drafted the manuscript. JV contributed to the study design, provided and cared for study patients, contributed to data acquisition and revised the manuscript critically. WH contributed to the presentation of our results and revised the manuscript critically. PF contributed to the study design (in particular the choice of the morphological criteria), and provided Montpellier patient data. DA contributed to the study design (in particular the choice of the morphological criteria) and provided cooperation with CLRC Val d'Aurelle. HZ conceived and introduced the use of low dose 4DCT in Geneva and contributed to data acquisition. MW provided collaboration with the Nuclear Medicine department in Geneva and provided and cared for study patients in the Nuclear Medicine department. OR provided collaboration with the Nuclear Medicine department in Geneva and assumed the overall responsibility from the Nuclear Medicine department. RM permitted to NP to develop this study in the Radiation Oncology department in Geneva, revised the manuscript critically and assumed the overall responsibility for the study. All authors read and approved the final manuscript.

\section{Competing interests}

The authors declare that they have no competing interests.

Received: 23 March 2011 Accepted: 24 June 2011

Published: 24 June 2011 


\section{References}

1. Perez CA, Bauer M, Edelstein S, Gillespie BW, Birch R: Impact of tumor control on survival in carcinoma of the lung treated with irradiation. Int J Radiat Oncol Biol Phys 1986, 12(4):539-47.

2. Rosenman JG, Halle JS, Socinski MA, Deschesne K, Moore DT, Johnson H, Fraser R, Morris DE: High-dose conformal radiotherapy for treatment of stage IIIA/IIIB non-small-cell lung cancer: technical issues and results of a phase I/II trial. Int J Radiat Oncol Biol Phys 2002, 54(2):348-56.

3. Kong FM, Ten Haken RK, Schipper MJ, Sullivan MA, Chen M, Lopez C Kalemkerian GP, Hayman JA: High-dose radiation improved local tumor control and overall survival in patients with inoperable/unresectable non-small-cell lung cancer (long-term results of a radiation dose escalation study). Int J Radiat Oncol Biol Phys 2005, 63(2):324-33.

4. Shimizu S, Shirato H, Ogura S, Akita-Dosaka H, Kitamura K, Nishioka T, Kagei K, Nishimura M, Miyasaka K: Detection of lung tumor movement in real-time tumor-tracking radiotherapy. Int J Radiat Oncol Biol Phys 2001, 51(2):304-310.

5. Ford EC, Mageras GS, Yorke E, Rosenzweig KE, Wagman R, Ling CC: Evaluation of respiratory movement during gated radiotherapy using film and electronic portal imaging. Int J Radiat Oncol Biol Phys 2002, 52(2):522-531.

6. Shirato $H$, Shimizu $S$, Kunieda T, Kitamura K, van Herk M, Kagei K, Nishioka T, Hashimoto S, Fujita K, Aoyama H, Tsuchiya K, Kudo K, Miyasaka K: Physical aspects of a real-time tumor-tracking system for gated radiotherapy. Int J Radiat Oncol Biol Phys 2000, 48(4):1187-1195.

7. Wolthaus JW, Sonke JJ, van Herk M, Damen EM: Reconstruction of a timeaveraged midposition CT scan for radiotherapy planning of lung cancer patients using deformable registration. Med Phys 2008, 35(9):3998-4011.

8. Keall PJ, Starkschall G, Shukla H, Forster KM, Ortiz V, Stevens CW, Vedam SS, George R, Guerrero T, Mohan R: Acquiring 4D thoracic CT scans using a multislice helical method. Phys Med Biol 2004, 49:2053-2067.

9. Starkschall G, Britton K, McAleer MF, Jeter MD, Kaus MR, Bzdusek K, Mohan R, Cox JD: Potential dosimetric benefits of four-dimensional radiation treatment planning. Int J Radiat Oncol Biol Phys 2009, 73(5):1560-5

10. Keall P: 4-dimensional computed tomography imaging and treatment planning. Seminars in Radiation Oncology 2004, 14(1):81-90.

11. Wolthaus JW, Sonke JJ, van Herk M, Belderbos JS, Rossi MM, Lebesque JV, Damen EM: Comparison of different strategies to use four-dimensional computed tomography in treatment planning for lung cancer patients. Int J Radiat Oncol Biol Phys 2008, 70(4):1229-38.

12. Barnes EA, Murray BR, Robinson DM, Underwood L, Hanson J, Roa WH: Dosimetric evaluation of lung tumor immobilization using breath hold at deep inspiration. Int J Radiat Oncol Biol Phys 2001, 50(4):1091-1098.

13. Hanley J, Debois MM, Mah D, Mageras GS, Raben A, Rosenzweig K Mychalczak B, Schwartz LH, Gloeggler PJ, Lutz W, Ling CC, Leibel SA, Fuks Z, Kutcher GJ: Deep inspiration breath-hold technique for lung tumors (the potential value of target immobilization and reduced lung density in dose escalation). Int J Radiat Oncol Biol Phys 1999, 45(3):603-11.

14. Balter JM, Lam KL, McGinn CJ, Lawrence TS, Ten Haken RK: Improvement of CT-based treatment-planning models of abdominal targets using static exhale imaging. Int J Radiat Oncol Biol Phys 1998, 41(4):939-43.

15. Wallis JW, Miller TR, Lerner CA, Kleerup EC: Three-dimensional display in nuclear medicine. IEEE Trans Med Imaging 1989, 8(4):297-303.

16. Underberg RW, Lagerwaard FJ, Slotman BJ, Cuijpers JP, Senan S: Use of maximum intensity projections (MIP) for target volume generation in 4DCT scans for lung cancer. Int J Radiat Oncol Biol Phys 2005, 63(1):253-60.

17. (Critical structures in): RTOG 0617, a randomized phase III comparison of standard- dose (60Gy) versus high-dose (74Gy) conformal radiotherapy with concurrent and consolidation carboplatin/paclitaxel+/- cetuximab in patients with stage IIIA/IIIB non-small cell lung cancer.

18. Seppenwoolde $Y$, Shirato H, Kitamura K, Shimizu S, van Herk M, Lebesque JV, Miyasaka K: Precise and real-time measurement of 3D tumor motion in lung due to breathing and heartbeat, measured during radiotherapy. Int J Radiat Oncol Biol Phys 2002, 53(4):822-834.

19. Giraud P, De Rycke Y, Dubray B, Helfre S, Voican D, Guo L, Rosenwald JC, Keraudy K, Housset M, Touboul E, Cosset JM: Conformal radiotherapy (CRT) planning for lung cancer (analysis of intrathoracic organ motion during extreme phases of breathing). Int J Radiat Oncol Biol Phys 2001, 51(4):1081-1092
20. Forster KM, Stevens CW, Kitamura K, Chang JY, Cox JD, Guerrero TM, Jeter M, Liao Z, Starkschall G, Komaki R: Changes of Tumor Motion Patterns During a Course of Radiation Therapy for Lung Cancer [abstract]. Int J Radiat Oncol Biol Phys 2003, 57(Suppl 2):S234.

21. Hernando ML, Marks LB, Bentel GC, Zhou SM, Hollis D, Das SK, Fan M, Munley MT, Shafman TD, Anscher MS, Lind PA: Radiation-induced pulmonary toxicity (a dose-volume histogram analysis in 201 patients with lung cancer). Int J Radiat Oncol Biol Phys 2001, 51(3):650-9.

22. Graham MV, Purdy JA, Emami B, Harms W, Bosch W, Lockett MA, Perez CA: Clinical dose-volume histogram analysis for pneumonitis after 3D treatment for non-small cell lung cancer (NSCLC). Int J Radiat Oncol Biol Phys 1999, 45(2):323-9.

23. Kwa SL, Lebesque JV, Theuws JC, Marks LB, Munley MT, Bentel G, Oetzel D, Spahn U, Graham MV, Drzymala RE, Purdy JA, Lichter AS, Martel MK, Ten Haken RK: Radiation pneumonitis as a function of mean lung dose (an analysis of pooled data of 540 patients). Int J Radiat Oncol Biol Phys 1998, 42(1):1-9.

24. Starkschall G, Forster KM, Kitamura K, Cardenas A, Tucker SL, Stevens CW: Correlation of gross tumor volume excursion with potential benefits of respiratory gating. Int J Radiat Oncol Biol Phys 2004, 60(4):1291-7.

25. Louie AV, Rodrigues G, Olsthoorn J, Palma D, Yu E, Yaremko B, Ahmad B, Aivas I, Gaede S: Inter-observer and intra-observer reliability for lung cancer target volume delineation in the 4D-CT era. Radiother Oncol 2010, 95(2):166-71.

doi:10.1186/1748-717X-6-78

Cite this article as: Peguret et al:: Breathing adapted radiotherapy: a 4D gating software for lung cancer. Radiation Oncology 2011 6:78.

\section{Submit your next manuscript to BioMed Central and take full advantage of:}

- Convenient online submission

- Thorough peer review

- No space constraints or color figure charges

- Immediate publication on acceptance

- Inclusion in PubMed, CAS, Scopus and Google Scholar

- Research which is freely available for redistribution

Submit your manuscript at www.biomedcentral.com/submit
C) Biomed Central 